\title{
Editorial
}

\section{Comentarios sobre la Memoria Institucional 2006-2007 del Ministerio de Salud}

Después de leer el informe presentado por la ministra de Salud, Dra. María Luisa Ávila Agüero, ante el presidente de la Asamblea Legislativa, en cumplimiento de lo que obliga la Constitución Política de la República, titulado "Memoria Institucional 2006- 2007" y que pueden encontrar para su lectura completa en la siguiente dirección electrónica: http://www. ministeriodesalud.go.cr/memorias.htm, he sentido la imperiosa necesidad de escribir un editorial sobre sus contenidos.

Lo primero que me llamó la atención es su estructura: clara, con definición de conceptos y excelentes gráficos, además de que cubre una gran cantidad de temas, todos tratados en forma seria y con honestidad - los logros se muestran tanto como los campos en los que no se han alcanzado mayores progresos-.

La organización del Ministerio está marcada por un liderazgo participativo y que acepta las ideas, pero exige responsabilidad intelectual para defenderlas y aún mayor para cumplirlas; esto, sin duda, ha permitido conformar un equipo motivado y que produce resultados muy claros en el informe.

La ministra insiste en su empeño por cambiar el paradigma de atención de la enfermedad por el de promoción de la salud. Se trata de un concepto básico y son numerosos los estudios que demuestran que cuando se invierte en combatir la enfermedad y no en prevenirla, los índices de salud no mejoran. Adicionalmente, se entiende muy bien la necesidad de involucrar los diferentes entes que participan en el proceso y que, con una actuación adecuadamente dirigida por el Ministerio, son de gran ayuda. Así, es notoria la colaboración de la OPS, de la Universidad y de otras entidades, las cuales con su participación han permitido al Ministerio cumplir su función rectora de la salud.

Es interesante la importancia que se le ha dado a la información, pues a pesar de los escasos recursos existentes, se ha invertido en tecnología, lo que ha permitido conocer los datos estadísticos fundamentales para tomar decisiones correctas.

Se hace hincapié en el papel de las intoxicaciones y se presenta un análisis de su incidencia y mortalidad desde 2002 hasta 2006, mostrándose en el último año un aumento de los casos y de la mortalidad, específicamente en los provocados por suicidio. En este campo en particular, los medicamentos no permitirán mejorar, solo lo hará la promoción de la salud.

Probablemente, uno de los mayores logros de 2006 es el resultado de la comparación entre los casos de dengue de ese año y los de 2005. Es impresionante la diferencia, sobre todo en las semanas de las épocas más lluviosas. Este es un logro en el que el paradigma de promoción de la salud muestra sus enormes ventajas. Fueron las acciones coordinadas con la CCSS, las municipalidades y otras entidades de la sociedad, las que han permitido eliminar reservorios donde se reproducía el mosquito trasmisor.

Se analiza la mortalidad general con énfasis en las principales causas y se determina que el primer lugar lo ocupan las enfermedades del aparato circulatorio, con una tasa de 38.1 por 10.000 habitantes, algo que puede abordarse mejor con medidas preventivas. El segundo lugar

ISSN 0001-6002/2007/49/3/138-139 Acta Médica Costarricense, $\bigcirc 2007$ Colegio de Médicos y Cirujanos corresponde a los tumores, con una tasa de 11.0, lo que indica la necesidad de diagnósticos más tempranos. 
La mortalidad infantil por 1.000 nacimientos se analiza desde 1990, cuando estaba en 15.3, hasta 2006, cuando ha bajado a 9.7, lo que es un poco más alto de la que se obtuvo en 2005 (9.2). El gráfico que analiza este parámetro por provincias es una información excelente, pues permite al Ministerio dirigir sus acciones en las provincias de Puntarenas, Limón y Guanacaste, donde las cifras superan el promedio.

El infarto del miocardio ha disminuido discretamente a partir de 2000, y la mayoría de los casos se presentan en personas de más de 65 años, edad en la que se descuida la promoción de la salud.

El tumor con mayor incidencia en el sexo femenino, es como en todas partes, el de piel con una tasa ajustada de 44.6 por 100.000 mujeres, seguido por el cáncer de mama (40.07). La mortalidad de los tumores la encabeza el cáncer de mama con una tasa de 13.14 por 100.000 mujeres, y se muestra un ligero ascenso en los últimos dos años; le sigue el cáncer de estómago, el cual refiere un descenso.

Las cifras de mortalidad en los hombres difieren en relación con las patologías: el cáncer de la próstata ocupa el primer lugar, con una tasa de 51.13 por 100.000 habitantes, seguido por el de la piel y el de estómago, que también, como en la mujeres, muestra una tendencia descendente.

Se analiza el programa de vacunación desde 2003 hasta 2006 y se muestran los altos porcentajes alcanzados por el programa, con cifras que llegan cerca del $90 \%$ para BCG, DPT3, VHB3 Y SRP. Los esfuerzos por dotar al país de 4 vacunas más: varicela, neumococo, tosferina para adolescentes y rotavirus son muy importantes. Así también, la formación de un grupo constituido por el Ministerio de Salud, la CCSS, el IMAS y la Junta de Protección Social, para financiar estas vacunas, es un esfuerzo que debe contar con amplio apoyo en procura de convertirnos en líderes en el campo.
Los desechos sólidos han sido un serio problema desde hace muchos años y no ha sido posible conseguir acuerdos al respecto. El Ministerio ha sido un coordinador entre las municipalidades y otras entidades para tratar de encontrar solución al problema. La declaratoria de emergencia en Tibás y las gestiones realizadas en Río Azul fueron algunos de sus logros. El proyecto "Ciudades Limpias" ha permitido orientar, conducir y asesorar a las comunidades, y con la ayuda de la Agencia de Cooperación Internacional Japonesa (JICA) se confeccionó un disco compacto educativo sobre el manejo integral de residuos.

La inversión en tecnología informática, computadoras y software llama la atención, y es lo que ha propiciado el acceso a información actualizada.

Dado que mi intención no era presentar un resumen cabal del informe, sino incentivar para que lo busquen en Internet y lo lean completo, terminaré comentando los datos del Gráfico No 3 "Gasto en millones de colones, Sector Salud, 2002-2006", donde se puede observar que el Ministerio de Salud, el INS, y la UCR no han aumentado su presupuesto en los últimos años; por el contrario, la CCSS, el ICAA y las municipalidades sí lo han hecho. La que muestra un mayor aumento en sus presupuestos es la primera (CCSS, con un 17\%). La diferencia en millones de colones es abismal, por ejemplo, entre el Ministerio que gastó en 2006 29.274.81 millones de colones, y la CCSS, con $533.843,40$. Tales cifras nos deben llamar a la reflexión y a esperar por parte de la Caja Costarricense de Seguro Social, una mejor utilización de tantos recursos.

Carlos Arrea-Baixech

Miembro de Número de la Academia Nacional de Medicina 